\title{
Poder y crisis. Ciclos de explotación y no-explotación minera en Cerro de San Pedro, México, y sus ecos contemporáneos (1950-2009)
}

\section{Hernán Horacio Schiaffini*}

Fecha de recepción: 7 de diciembre de 2017. Fecha de aceptación: 2 de junio de 2018

\begin{abstract}
Resumen
El siguiente artículo indaga cómo algunos segmentos de la población de Cerro de San Pedro, pueblo minero del centro de México, percibieron la alternancia de marcados ciclos de explotación y no-explotación de los yacimientos minerales de la zona entre 1950 y 2009. Para ello, se transcriben fragmentos de entrevistas realizadas entre 2007 y 2009 con miras a analizar de qué manera los habitantes de la región explican, a los demás y a sí mismos, estos ciclos que, atados a la economía mundial, los afectaron durante todo el siglo XX. Además, teniendo en cuenta la problemática actual de Cerro de San Pedro, inmerso en un conflicto relativo a la oposición a la minería de oro a cielo abierto, se evalúa qué elementos de una supuesta "tradición minera" tienen peso en las disputas locales contemporáneas.
\end{abstract}

Power and crisis. Mining cycles of exploitation and none xploitation in Cerro de San Pedro, México, and their contemporary echoes (1950-2009)

\begin{abstract}
The current paper studies how some segments of the population of Cerro de San Pedro, a mining town in central Mexico, perceived the alternation of marked cycles of exploitation and non-exploitation of mineral deposits in the area during 1950 and 2009. Fragments of interviews conducted between 2007 and 2009 are transcribed, in order to analyze how the inhabitants of the region explain to others and themselves these cycles of investment and divestment. Undoubtedly tied to the world economy, those cycles affected them throughout the 20th century. Moreover taking into account the current problem of Cerro de San Pedro, immersed in a conflict related to the opposition to open-pit gold mining, an evaluation of the elements of an alleged "mining tradition" that still have an impact on contemporary local disputes is presented.
\end{abstract}

* Consejo Nacional de Investigaciones Científicas y Técnicas - Universidad Nacional de la Patagonia "San Juan Bosco" (CONICET-UNPSJB). Esquel, Provincia de Chubut, Argentina E-mail: hernanschiaffini@gmail.com
Palabras clave

minería ciclo económico crisis conflictos socio-ambientales

Key words

mining industry economic cycle crisis

socio-environmental conflicts 


\section{Introducción}

Los ciclos económicos son experimentados por las poblaciones que los sufren de distintas maneras. Aquí abordaremos algunos relatos orales registrados en el pueblo de Cerro de San Pedro, San Luis Potosí, México entre 2007 y 2009. Este pueblo, fundado por los conquistadores españoles en el siglo XVI, tuvo su destino atado a los yacimientos minerales de su subsuelo: hierro, plomo, zinc y fundamentalmente oro y plata. Hoy en día, debido a la operación de la empresa minera San Xavier -subsidiaria mexicana de la transnacional Gold Corp- no sólo se encuentra inmerso en un conflicto de tipo "socio-ambiental" (Martínez-Allier, 2006; Walter, 2009), sino que corre riesgo de desaparecer -al menos parte de su patrimonio material e infraestructura- y su caso ha sido objeto de diversos análisis (Costero Garbarino, 2008).

Una población que hacia fines de la década de 1940 contaba con alrededor de cinco millares, se había reducido hacia 2009 a menos de cien habitantes. Esto sin dudas, nos habla de procesos más largos y complejos que los que la naturaleza de la minería de oro actual encarna. Surgió así la necesidad de indagar la historia de Cerro de San Pedro, una historia que sólo ha sido escrita fragmentariamente (Monroy Castillo y Calvillo Una, 1997) y de la que este trabajo se propone ser una pieza más.

La hipótesis que guía este trabajo es que las distintas etapas de "bonanza", "no-explotación", "abandono", "migración" y el actual "retorno de la minería" conllevaron reconfiguraciones profundas en la estructura de poder local. No es solamente una "crisis internacional" lo que se recuerda o describe sino las consecuencias políticas de esas crisis. Aquí queremos evaluar de qué manera dichos procesos históricos influenciaron en los posicionamientos que se verificaban en el conflicto minero de Cerro de San Pedro hacia 2009.

Proponemos que las estructuras de poder, formales e informales, vigentes en dicho momento en la localidad -y que más abajo describiremos a través de la figura del "caciquismo" (Bartra, 1978)- se sustentaban y/o legitimaban, entre otras cosas, en ciertos hechos específicos que habían dejado marcas particulares en la memoria de los habitantes de Cerro de San Pedro. Y además, que esos hechos específicos se conectaban fundamentalmente con las transformaciones experimentadas por la población ante la llegada y la retirada de grandes empresas mineras. De tal modo, en las disputas contemporáneas se verificarían los efectos locales de las historias de mediano y largo plazo. El control político del pueblo y el consenso en torno de las explotaciones mineras van, de acuerdo con esto, de la mano y se basan en las disputas y alianzas que ejercen distintos sectores de la población.

A partir del análisis de un período histórico que va de 1950 hasta 2009 intentaremos demostrar que los procesos de explotación/ no explotación de los yacmientos minerales se correlacionan con variaciones en la estructura de poder local. Durante la primera mitad del siglo XX la hegemonía en Cerro de San Pedro estuvo ligada al funcionamiento de una gran compañía estadounidense, la American Smelting and Refining Compañy (ASARCO). ${ }^{1}$ Tras su retiro hacia 1950 existió un intento alternativo de liderazgo local basado en cooperativas mineras. El fracaso económico de dichas cooperativas posibilitó la emergencia de una nueva facción, cuya dirigencia fue la que logró refrendarse hacia fines de la década 1990 estableciendo alianzas con una nueva empresa minera, San Xavier. 


\section{El conflicto minero en Cerro de San Pedro}

Cerro de San Pedro está ubicado en el Estado de San Luis Potosí, en el centro de México. Es un municipio pequeño, de menos de 4.000 habitantes, cuya cabecera es el propio pueblo de Cerro de San Pedro, donde vivían unas 100 personas en 2009. Hay que destacar, como se adelantó, que este poblado estaba habitado hacia 1950 por más de 5.000 personas. Los procesos migratorios de los años siguientes no sólo explican este despoblamiento sino también, como veremos más adelante, algunos canales de las pujas políticas.

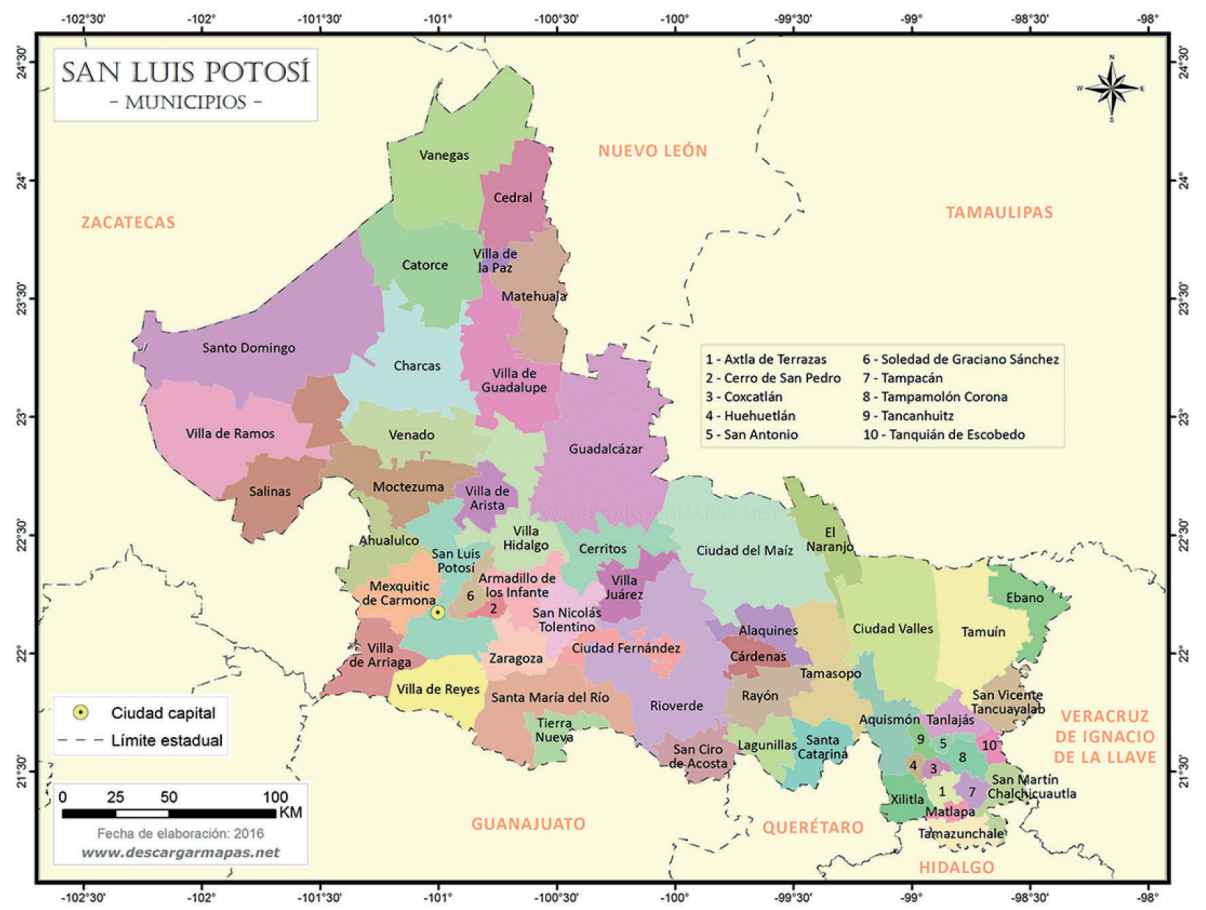

Mapa. San Luis Potosí, México.

Cerro de San Pedro está en lo alto de unas sierras, a solo media hora de viaje de la capital del Estado, la ciudad de San Luis, habitada por más de un millón de personas. Aunque San Pedro es la cabecera y sede del poder ejecutivo y del ayuntamiento, El Portezuelo es la localidad más numerosa del municipio concentrando más de 2.000 habitantes; es decir, más de la mitad de la población total mientras el resto se distribuye en siete pueblos pertenecientes al mismo municipio.

Casi la totalidad de los habitantes de Cerro de San Pedro estuvieron desempleados entre 2008 y 2009; intentaban ganarse el sustento a través de la venta de distintos productos y servicios turísticos que ofrecían a los visitantes que llegaban en buen número los fines de semana, provenientes de la capital o de otros Estados.

Cerro de San Pedro fue un enclave minero desde su origen a fines del siglo XVI. Como muchos pueblos mineros tuvo bonanzas y decadencias marcadas por los vaivenes de los precios de los metales. ASARCO funcionó en San Pedro hasta 1948, siendo la última gran compañía que trabajó los yacimientos del lugar hasta la llegada de Minera San Xavier. Entre 1950 y 1990 el pueblo vivió un estado de profunda desinversión y abandono. No existieron proyectos 
de explotación minera ni inversiones que revitalizaran la economía local. Pequeñas cooperativas mineras intentaron trabajar y fracasaron. La mayoría de la población emigró y así San Pedro llegó a su situación actual, derruido y despoblado, al punto de que se lo promocionaba turísticamente como "pueblo fantasma".

A mediados de 1996 hizo su aparición Minera San Xavier. Compró algunas concesiones y derechos de explotación y propuso la explotación del Cerro de San Pedro. Hoy la región está envuelta en un conflicto de los llamados "socioambientales" (Martínez-Allier, 2006; Alimonda, 2008; Delgado Ramos, 2010): disputas que, a grandes rasgos, giran en torno del control de los "recursos naturales" -también llamados, desde una perspectiva diferente, "bienes comunes" (Svampa, 2008)-, el manejo de "pasivos ambientales" y los sentidos de términos como "desarrollo", "naturaleza" y "contaminación". En Cerro de San Pedro la situación gira, básicamente, alrededor de la oposición al proyecto minero con los argumentos de evitar la contaminación del agua y la destrucción material del poblado, de gran valor patrimonial.

Minera San Xavier explota los yacimientos en medio de una fuerte resistencia de distintos sectores de la población del Estado de San Luis Potosí, que constituyeron el Frente Amplio Opositor a Minera San Xavier (FAO). Éste desarrolló una poderosa militancia contra la empresa minera y en favor de la protección patrimonial, ambiental y social de Cerro de San Pedro y sus alrededores. En algunas líneas de acción tuvo éxito pero nunca consolidó una fuerza numerosa ni consiguió volcar en su favor a la opinión pública. La lucha en el plano jurídico y legal fue la que más frutos rindió, obtuvo varios puntos cruciales respecto de la legalidad del estudio de impacto ambiental y ciertos permisos ejidales, llegando a paralizar las operaciones de la mina en varias ocasiones. Sin embargo la empresa retomó sus actividades y la Secretaría de Medio Ambiente y Recursos Naturales (SEMARNAT) y la Procuraduría Federal de Protección Ambiental (PROFEPA), instituciones federales que ejercen el control de este tipo de emprendimientos, renovaron sus permisos al poco tiempo. Así, en 2017 la empresa encaraba el último tramo de la explotación planeada y existían debates en torno a prolongarla de manera subterránea.

\section{Caciquismo y poblaciones locales en México}

Antes de adentrarnos en la historia de Cerro de San Pedro es necesario definir y explicitar algunas cuestiones conceptuales a fines de hacer más clara la exposición. En particular, el problema del caciquismo es central. La voz "cacique", que los conquistadores españoles tomaron de las jefaturas taínas del Caribe y generalizaron hacia todo tipo de liderazgo indígena -sin importar su heterogeneidad- continúa teniendo un doble sentido, al menos en México. Por un lado, es el término con el que los propios actores locales designan un tipo de liderazgo social autoritario, vinculado a influencias informales y territorios marginales. Por el otro, es un concepto elaborado por la antropología y la sociología mexicanas que intenta explicar las formas políticas que adopta en ciertas regiones la articulación entre las relaciones sociales capitalistas y las dinámicas locales, que pueden ser campesinas, mercantiles o de algún otro tipo pero suelen estar signadas por la informalidad.

En las propuestas de Roger Bartra y equipo (1978), y sin adentrarnos por cuestiones de espacio en los detalles de estos desarrollos teóricos, diremos que el cacique es un mediador, un intermediario que expresa en la esfera política la 
articulación entre el mercado y las formas de producción locales, entre el sistema formal-legal y el mundo de las relaciones interpersonales, entre el Estado y la comunidad local. Los caciques adquieren su legitimidad de ambos mundos, el del Estado y el mercado y el de la comunidad local: son los interlocutores para ambas esferas y quienes transportan los mensajes que circulan entre una y otra. Suelen ocupar posiciones de gobierno o de gestión, como jefaturas municipales, o ser funcionarios de ministerios o instituciones menores. Para Bartra, en este proceso de "traducción" los caciques garantizan la continuidad de la explotación que la comunidad local sufre a manos del mercado.

Los caciques se refrendan "hacia abajo" mediante complejos sistemas de lealtad, patronazgo, compadrazgo, deudas y vínculos del parentesco. Al decir de Javier Auyero (1998) pueden "resolver problemas" u obtener beneficios para los pobladores a quienes lideran. En segundo término, la apelación a la violencia puede ser también una de sus prerrogativas. En el caso mexicano, durante el siglo XX y tras la Revolución de 1910 (Gilly, 1982) en múltiples espacios territoriales existió una estrecha vinculación entre los caciques, el Partido de la Revolución Institucional (PRI) y las organizaciones sindicales. Cerro de San Pedro no fue la excepción en este aspecto e intentaremos demostrar de qué manera la reconfiguración de las distintas etapas productivas de este territorio conllevó la transformación de las hegemonías de diferentes caciques y que, ligado a esto, los posicionamientos que hacia 2009 podían leerse en torno del conflicto minero no estaban lejos de aquellas disputas.

\section{ASARCO en San Pedro, una caracterización}

Como señalamos, ASARCO fue una sociedad minera fundada en 1899. Daniel Guggenheim y William Rockefeller fueron sus principales socios, en 1912 sumaron a J. P. Morgan y a Jacob Schiff para minar cobre en Alaska. ASARCO se dedicó de lleno a la explotación de la minería en territorio mexicano, trabajando minas en varios Estados del norte, como Cohauila, Sonora y San Luis. Junto con Greene Cananea Copper Co. y Cananea Central Copper Co. era la empresa minera más grande de México durante las primeras décadas del siglo XX. La influencia de la familia Guggenheim fue notable, puesto que además de ASARCO controlaba una gran cantidad de empresas subsidiarias (Sariego et al., 1988).

ASARCO es un buen ejemplo histórico de la llamada minería de enclave: con fuertes inversiones y procesos productivos que trabajaban con tecnología de punta lograban excelentes rendimientos y el control de todo el proceso productivo; desde la extracción del mineral hasta la fundición y el refinamiento. Posteriormente el producto se exportaba a EE.UU. La integración vertical y la explotación de múltiples yacimientos en el norte y centro de México hicieron de ASARCO una compañía enorme, con una extensa planta de trabajadores. Como en ocasiones las minas estaban ubicadas en regiones alejadas o deshabitadas, la propia empresa se encargaba del diseño de las ciudades como ocurrió en Nueva Rosita (Coahuila):

Los trabajadores fueron traídos de La Rosita -poblado cercano en donde había estado la sede de la empresa-, y ubicados en la colonia Seis. La empresa edificó la iglesia, el mercado, la comisaría, la estación del ferrocarril, los baños públicos, el teatro, una serie de restaurantes y comercios y hasta un club con su boliche y sala de billar para los "nativos". 
2. La puesta en marcha de la mina de Cerro de San Pedro por parte de Minera San Xavier también implicó la relocalización de uno de los pueblos del municipio, La Zapatilla. La empresa construyó otro pequeño pueblo a pocos kilómetros del emplazamiento original, con iglesia incluida.

3. En todos los casos utilizamos seudónimos para mencionar a nuestros entrevistados.
La colonia norteamericana para el personal directivo, con viviendas de lujo, hotel y hospital fue erigida en el lugar más alto de la población, lejos de la planta y sus chimeneas. En la colonia del Seis se construyeron diferentes tipos de vivienda obrera de acuerdo a la categoría laboral y estado civil de sus usuarios, incluyendo dormitorios colectivos para solteros y servicios sanitarios colectivos para los mineros mexicanos "teniendo en cuenta el nivel de educación que prevalece entre ellos". A juicio de los directivos de ASARCO Nueva Rosita fue una "ciudad cuidadosamente planeada, agradable, confortable e higiénica (Sariego et al., 1988: 109).

Sin llegar a tales extremos la misma orientación se desarrolló en Cerro de San Pedro, donde aun se ven las ruinas de estructuras e instalaciones de este tipo abandonadas desde hace más de 60 años: desde habitaciones hasta una estación de ferrocarril y canchas de baloncesto que hoy, ocasionalmente, se usan como estacionamiento. Gran parte de esta infraestructura local durante la primera mitad del siglo XX fue producto de los trabajos de ASARCO ${ }^{2}$ Como veremos más adelante, el desmantelamiento y el aprovechamiento en pequeña escala de tal infraestructura acumulada fue una de las estrategias empleadas por la población de Cerro de San Pedro para sobrevivir en los años posteriores a la retirada de la compañía.

El Secretario Municipal del pueblo, González, ${ }^{3}$ sintetizó la historia de San Pedro en pocas líneas:

Así es...bueno, aquí la minería empezó, ya deben de saber, ya deben tener historia, verdad, desde el año de mil...Bueno se supone que se funda en el año de 1492 [sic] con los españoles, con el Capitán Caldera, que fue uno de los precursores de los que encontraron aquí el mineral en el Cerro de San Pedro. Al lado de él se fundó la Ciudad Capital. A través de estos 415 años han llegado diferentes compañías aquí al pueblo de San Pedro. En los años que comentaban ahí, cuarentas, estuvo la compañía minera ASARCO la, bueno, ahorita sería la penúltima, verdad. (Entrevista, Cerro de San Pedro, 2007).

González señaló tres hitos: el descubrimiento, ASARCO y la llegada de Minera San Xavier.

La presencia de ASARCO en San Pedro es algo que refiere cualquiera que narre la historia de este pueblo, aunque en general se hable más del abandono y cierre de las minas que del período de "bonanza". Sin embargo, este período es importante pues sentó las bases de consolidación de cierta interconexión entre la política formal e informal, el sindicalismo y las relaciones familiares y personales, como señala Bartra (1978) para otras zonas de México. Esta red de alianzas tomó la forma de una hegemonía familiar que se ejerció sobre el municipio durante varios años y se quebró con la partida de la empresa norteamericana. Dicha red se personificaba en los miembros del Sindicato de Nacional de Trabajadores Mineros Mexicanos, cuadros técnicos de la empresa minera -entre quienes se contaban algunos antepasados de miembros del FAO hacia 2009- y los rectores de la escuela del pueblo, apoyados por la burocracia de la Secretaría de Educación Pública (SEP), actor políticamente muy dinámico en muchos puntos del territorio mexicano. Aunque no exento de conflictos, donde se verificaban las tensiones entre corporaciones estatales y privadas e intereses facciosos al interior del PRI, podemos afirmar que este plexo de actores tuvo profunda influencia en el gobierno de Cerro de San Pedro durante la primera mitad del siglo XX. Tomando esta situación como punto de partida inicial, revisaremos de qué modos se trastocó a partir de los 
cambios acontecidos desde 1950 y esto se hace evidente al examinar la ruptura que significó la partida de ASARCO.

\section{ASARCO abandona San Pedro: de la explotación a la no- explotación empresarial y el cambio en las relaciones de liderazgo local}

ASARCO abandonó Cerro de San Pedro a fines de la década de 1940, motivada principalmente por dos razones: a) el agotamiento del cerro en virtud de la tecnología que hacía rentable su explotación y b) las huelgas que los obreros mineros encararon contra la empresa durante varios años, como parte de un proceso de alcance nacional. Efectivamente, durante esta década los conflictos entre empresas mineras y trabajadores se intensificaron. Ya en 1940 hubo huelgas en Cananea y Nueva Rosita, que se extendieron hasta febrero de 1941 aunque sin grandes logros; y fueron el prolegómeno de la huelga general que se desataría en 1944. Los obreros reclamaban mejores salarios y la implementación del contrato colectivo único para toda la rama. El gobierno de Manuel Ávila Camacho, ${ }^{4}$ en el contexto de la Segunda Guerra Mundial (1939-1945), no estaba dispuesto a tener las minas cerradas durante mucho tiempo y urgió a las partes a llegar a acuerdos por sección (Sariego et al., 1988). Sin embargo al año siguiente estallaron nuevas huelgas, conocidas en la literatura como "huelgas plateras" puesto que se debían a los reclamos de los mineros de plata: el fin de la guerra había impulsado los precios de este metal, de modo que los trabajadores se lanzaron por aumentos salariales del $40 \%$. Sin alcanzar las dimensiones de la huelga general de 1944, los conflictos sindicales continuaron hasta entrada la década de 1950. (Sariego et al., 1988: 239-240).

ASARCO trabajaba en varias regiones del país, extrayendo carbón en el norte y metales en el centro, pero ya estaba abandonando Cerro de San Pedro cuando estalló la huelga. De hecho la huelga allí se debió a que la empresa no garantizaba la reubicación en otras plazas de sus empleados en San Pedro y dejaba aparentemente incumplidas algunas obligaciones de pago. Claudia tenía unos treinta años. No nació ni vivía en San Pedro sino que se había criado en San Luis Potosí pero trabajaba para Minera San Xavier administrando una especie de módulo de información pro-minero en el centro del pueblo. Era un local que recibía a los visitantes y turistas para divulgar los beneficios de la minería y la importancia de la actividad. En una charla que sostuvimos decía que:

C: y cuando minera ASARCO, por el 49-50 se va, liquida a los mineros. Pero los liquida no al 100\%, los liquida...dicen las personas que acá, que eran niños y ahora lo platican, que iban con las chaquetas los mineros y agarraban un montón de dinero y les decían "ten, ten, ten, ya!"

Yo: Y esa era la liquidación.

C: Esa era la liquidación ¡Cuando era mucho mayor! Una liquidación aquí, cuando una empresa se va, es liquidarlos al 100\%. Seguramente los han de haber liquidado al 10 o al 20\%. Cuentan también que en otras mineras, rumbo a Matehuala, el pago o la liquidación era con pala. Eran monedas de oro y plata y las paleaban. Y ese era la liquidación ¡Que diferencia! Y aquí no. Entonces cuando se va minera ASARCO...pues ellos ya habían ganado mucho terreno en lo que es excavación de minas. Y dijeron "pues me voy. Me voy, pero aparte, los friego" y empezaron a dinamitar todo lo que habían hecho, para derrumbarlo. Para que nadie, para que ninguna empresa viniera ya a agarrarlo, como quien dice "pásale a lo barrido". Ajá, y para que las mismas personas de aquí no se robaran el mineral. Lo dinamitan. Entonces cuando vienen las otras empresas,
4. Presidente de México entre 1940 y 1946. 
5. Varias personas nos refirieron esto, aunque asignándole distintos grados de importancia; se dice que hay cerca de $300 \mathrm{~km}$. de túneles debajo de San Pedro, la mayoría abandonados hace decenas de años.

6. Son físicamente montañas de piedras que se pueden encontrar al aire libre en distintos puntos del pueblo. los demás años, que si vemos que desde el 48, 49, que se va ASARCO al 70 ¡son 20 años! En veinte años no hubo nada. Pero esas empresas -en los 70- solamente vinieron a hacer labor de exploración (Entrevista, Cerro de San Pedro, 2007).

En la construcción discursiva de Claudia la liquidación a los obreros adquiría dimensiones casi mitológicas, con monedas de oro acarreadas en pala y pisos cubiertos de billetes. Sin embargo, ella intentaba señalar la desprolijidad con que supuestamente se hizo en Cerro de San Pedro, donde sólo se liquidaba a quien lo reclamaba y según ella, rápido y mal. En segundo lugar, enfatizó la destrucción dejada por ASARCO: los actos de sellar las minas, ${ }^{5}$ el depósito de escorias y descartes de los tiros mineros en las calles del pueblos, donde quedaron expuestos a los elementos ${ }^{6} \mathrm{y}$, en general, todo el abandono "irresponsable" que hizo la antigua compañía y que, por el contrario, Minera San Xavier decía estar dispuesta a subsanar como parte del plan de remediación de su propio proyecto. Pero hacia 1950, entonces, San Pedro se había quedado sin empresa, sin trabajo y con los desechos de las explotaciones encima. Julián López, de entre 60 y 70 años y uno de los referentes locales del FAO contra Minera San Xavier, nos decía:

J: Sí. Cuando este pueblo se abandonó en 1948, se fue yendo la gente poco a poco. Y...la escuela, cuando íbamos a la escuela ya empezaba a faltar gente "Fulano" ...y no está. "Y Mengano..." [pasaban lista] y tampoco está, familia que se fue. Yo cuando entré a la escuela fue en el 1950, éramos 700 niños. Cuando salí... (Entrevista, Cerro de San Pedro, 2008, la aclaración es nuestra).

Y no sólo afectó al municipio de San Pedro:

J: No, no, no. Bajó la población en el municipio y en los pueblos circunvecinos, digamos, la ranchería. Pero también bajaron aquí...este municipio, ahora es Delegación, se llamaba Pozos. Bajó, bajó también. Soledad. También bajó ¡En la Ciudad Capital bajó el comercio! Yo he escuchado, no sé si será cierto, que faltaba un millón de pesos, creo, diarios, en el banco. Era mucho dinero para aquella época! .Y ¿por qué? Porque era plata que salía de la minera, de la boca, de la mina.

Pero sí, este...sí se vino todo abajo (Entrevista, Cerro de San Pedro, 2008).

Y el secretario municipal González, quien antes nos había descrito brevemente la historia del poblado, señalaba:

S: De ahí, bueno, el pueblo quedó sin trabajo y la gente decidió de abandonar también el pueblo. Es por eso que la gente se fue retirando, abandonando sus fincas, y de ahí, de esos años a 1998, cuando llega Minera San Xavier (Entrevista, Cerro de San Pedro, 2007).

Los datos censales del Instituto Nacional de Estadística y Geografía (INEGI) confirman estos dichos: a partir del abandono de San Pedro por parte de ASARCO, el pueblo comenzó un profundo proceso de despoblamiento. Pero todo el municipio sufrió las consecuencias de la detención de actividades en el yacimiento. Los afortunados se iban con empleo a otras minas de ASARCO. Julián sin embargo era más joven que estos empleados y se quedó en San Pedro varios años más. Me cuenta su historia como parte de su biografía escolar:

J: Yo fue como que me gustaba mucho la escuela porque duré como ocho o nueve años [risas]. Nunca terminé mi primaria. Y no es que no la terminé por falta de inteligencia, no. Fue por las políticas de los maestros, que se iban, otro 
que no nos enseñaban, que llegó un maestro, muy buen maestro, yo iba en cuarto año y me regresó a segundo año. Y para uno es gravoso. Para el pobre. Porque otra vez libretas, otra vez lápices y todo eso y el esfuerzo de dos años ¿no? Nosotros teníamos muy escasos recursos para comprar lápiz a cada rato, para comprar libreta. Y...luego, luego, los maestros que se pasaban de roscas, que no le llevaban a uno bien. $\mathrm{Y}$ bueno, a todos nos pasaron a perjudicar. Yo iba al cuarto, quinto grado y me bajaron al segundo, tercero. $Y$ ya al final, como me quedé, a los trece, catorce años. Ya iba yo para catorce años. Y ya el maestro que nos daba clases de quinto año, de cuarto año, y no estábamos reconocidos. Entonces era la Dirección de Educación Pública. En la dirección no estábamos en el censo. Y como no estábamos en el censo, no nos reconocían. Y mucho esfuerzo para ir a la Ciudad Capital [...] por el Colegio. Por ahí anduvimos metidos, por un lugar que se llama La Garita. Todavía cumpliendo el sexto año. Lo hicimos. Firmaron el certificado, pero no nos lo dieron porque no estábamos reconocidos. Pues ni modo. Decepcionados (Entrevista, Cerro de San Pedro, 2008).

Aún cuando se deslizan en el discurso de Julián otros elementos para pensar un enfrentamiento entre la familia López y la estructura burocrática educativa, el fracaso escolar es planteado como causa de su partida hacia otras latitudes.

A: Me fui a México, pues. A través de mi padre me fui a México y allá volví a meterme a la primaria nocturna. Pero como allá trabajábamos un día sí, otro día no, a la escuela íbamos un día sí un día no.

Yo: ¿De qué trabajaba? ¿Qué hacía en México?

A: Yo en México trabajé en el Rastro de Ferrería. ${ }^{7}$ El rastro más grande de la ciudad de México. No era matancero, era velador, era cuidador. Muchos éramos, muchísimos. Y este...y ya llegando el mes de Octubre llegan y me dicen "usted, usted ni pierda su tiempo porque no le voy a pagar" “ ¿Ah si...?” No, dije, vayan a la... [risas]. Pues no es que no haya yo...yo tenía ganas [de estudiar]. Pero no había muchas oportunidades. Ahora ya tengo que, 63, 64 años (Entrevista, Cerro de San Pedro, 2008).

Julián pasa varios años en México ${ }^{8}$ y tiene a sus hijos allí. Sin embargo, como muchos otros, nunca rompe los lazos que lo unen a Cerro de San Pedro. Vuelve a visitar al menos una vez al año y siempre se presenta para la fiesta patronal. Tal vinculación se sostendrá y permitirá, más adelante, su retorno.

Una vez que ASARCO se retiró del pueblo, la memoria de los habitantes registra algunas catástrofes naturales: ciclones, tormentas, inundaciones. No es Julián el único que me las ha relatado, pero sí de quien lo he registrado:

J: Bué, se va la gente en 1950, 51, 52, se va la gente. En el 55, creo que en el 55, caen tres ciclones.

Yo: ¿Tres ciclones?

J: Tres ciclones. Seguiditos, órale. Empiezan en Agosto y terminan hasta Noviembre. Todo lo que es la ciudad ¿Vio acá en la orilla de la ciudad?

Yo: Sí.

J: Bueno, mucho, mucho más acá, donde empieza el caserío, todo eso era una laguna casi hasta llegar a la ciudad. Una laguna, pero grandísima. Una lagunota. De toda el agua que bajaba de aquí, que bajaba de los arroyos ¿Y qué pasa? Que no se cocinaba con gas, no se cocinaba con luz eléctrica. Se cocinaba con leña. Pero todo estaba mojado. Mucha gente pues se iba a tumbar las vigas de las casas que estaban desocupadas, para poder comer. No, no fue un vandalismo por ser vandalismo. A mí me tocó. No había con qué quemar. Y otros se iban a la mina, lo que sabían dónde, y sacaban palos de la mina y ahí los partían
7. Es un importante matadero y frigorífico de la ciudad de México DF.

8. Dice ser pionero en la ocupación de terrenos en Santo Domingo, Coyoacán, durante la década de 1970 y haber tenido una casa allí, hecho que confirman otras personas. 
dentro de la mina [...] Y les decía “¿qué?" y respondían "pues ya me voy, para otra parte". Y al rato mandaba por sus chamacos, por su señora y ya se iba. Y te pedían que cuidaras las macetas. "No y que hay que dar agua, cuidar las macetas" y ¿Y quién iba a andar acarreando agua para las macetas? No, hombre [risas] (Entrevista, Cerro de San Pedro, 2008).

Aquí hay varios puntos para tener en cuenta. En primer lugar, tras asociar el cierre de la mina con los cataclismos naturales, Julián nos dice que se hizo cuestión de supervivencia quemar los muebles, las vigas de las casas de los migrantes, los andamios que sostenían los tiros mineros, etc. Este punto es discutido por otras personas del pueblo, quienes acusan a quienes no migraron de haber saqueado las casas y pertenencias de quienes sí lo hicieron. Haciendo un ejercicio de descrédito ahora en el sentido inverso, hablaban de "la historia negra de los López", exigían que preguntara a sus familiares "quiénes realmente eran". Laura me decía:

L: Lo que pasa es que en 1948 cuando...bueno eso fue mi papá y mi abuelo porque yo nada que ver, verdad, lo que pasa es que mucha gente se fue buscando trabajo y lo único que sabía era trabajar en la mina, entonces se iban a pueblos mineros. Y cuando se iba la mayoría de la gente se llevaba su ropa, sus papeles, pero dejaban cama, estufa, todos sus muebles...lo que hacían era poner un candado a su puerta y ya. Entonces la gente que se quedó aquí del 48 al 70 ¿qué hizo?: "ya no tengo leña", entonces tumbaban una puerta para la leña. Voy y me meto a una casa y la saqueo y vendo sus cosas. Un saqueadero [sic] del 48 al 70 de la gente que se quedó aquí a saquear lo que quedaba (Entrevista, Cerro de San Pedro, 2008).

No fueron los López los únicos en recurrir a estas "estrategias" de "saqueo". Muchas familias del pueblo hicieron lo mismo. Ernesto, que tiene unos 60 años actualmente, es ejidatario y también se crió en San Pedro, aunque hoy vive en San Luis Potosí, nos contaba cosas similares. Y además de quemar, usar y vender lo que podían, separaban descartes minerales de las pilas sulfuradas. Los desechos que ASARCO había dejado en las calles incluían rocas con altos contenidos de plomo por ejemplo, que en su momento no había sido fundido. Cuando el precio internacional del metal lo hacía viable las familias recurrían a esos depósitos, cargaban piedras que contenían metales y las vendían por peso a la fundidora. Incluso los niños buscaban esas rocas entre las montañas de metales contaminantes, para venderlas. Es decir, sobrevivían mediante la explotación de lo que ASARCO había tirado a la basura y que en aquel nuevo contexto se convertía en un recurso. En síntesis, el abandono de ASARCO repercutió en diferentes dimensiones de la vida cotidiana de Cerro de San Pedro. Migración, saqueo y pobreza se hicieron habituales. Pero además, en el ámbito político, la desintegración de la estructura que alimentaba al sindicato minero y los cuadros técnicos de la empresa desarticuló las redes de poder políticos existentes hacia 1950.

En este período aparecieron actores "nuevos": los gambusios solitarios y los mineros cooperativistas. El secretario municipal decía:

S: En esos 50 años la gente comenzó a trabajar a base de lo que le dicen "gambusinos": meterse a las minas a buscar mineral.

Yo: ¿Las minas que ya estaban excavadas?

S: Sí, lo que ya estaba excavado ellos seguían, le llaman "vetas", donde va el mineral, ¿verdad? A escarbar, a sacar en costales, en carretillas y así se mantuvo el pueblo durante esos 50 años. Llegó a haber tres, cuatro encargados, bueno, 
tres, cuatro dueños que se encargaban de trabajar ese tipo de el mineral. Posteriormente ellos mismos, bueno, el mineral que sacaban lo llevaban directamente a la Industrial Minera México. Después ellos tuvieron aquí sus propias plantitas de beneficio, como lo que está trabajando ahorita MSX lo empezaron a trabajar aquí dos o tres personas, comenzaron a trabajar lo que es a base de cianuración.

Yo: Ah, ya utilizaban el método de cianuración.

S: Sí, sí, nada más que pues era muy lento, verdad, lo que sacabas se encarpía hasta que no llenabas una pileta. Aquí hubo dos personas que manejaban ese proceso. Acá donde estaban las instalaciones de la MSX había otras dos personas que trabajaban a base de este trabajo.

Yo: ¿Artesanalmente, diríamos?

S: Sí, sí, pues se sacaba muy poco, verdad (Entrevista, Cerro de San Pedro, 2007).

Según narra Julián López, había dos tipos de mineros:

J: Había dos clases de trabajadores, también. Había unos que se juntaban con otros, cinco, seis personas y sacaban el metal.

Yo: Se asociaban.

J: Sí. Y sacaban, digamos una cantidad de veinte, veinticinco toneladas de mineral. Eran buenos para trabajar, para cargar. Las carretillas esas que vieron, no ruedan fácilmente. Ahora hay carretillas de aire. Pero en la espalda sacaban el metal. Pero ellos hacían contrato. De todos modos las concesiones mineras existían, existían dueños. Quién sabe dónde andarían, pero existían dueños. Yo: Ahh, entonces ellos trabajaban para el dueño.

J: ¡Sí! Al dueño le pedían permiso para trabajar y hacían contrato con el dueño. Entonces ese mineral lo llevaban a la fundición de García. De la fundición de García, mandaban los valores a EE.UU y de ahí para acá ya venían las liquidaciones. Duraban un mes las liquidaciones.

Yo: ¿Desde que les llevaban el mineral hasta que les pagaban tardaban un mes? J: Un mes. Había veces que salían buenas las liquidaciones. Pero había veces que salían con números rojos. Porque no tenían cuidado o por la bajada de los metales. Y cuando subían, aunque metieran poquito te daban una buena ayudada. Y luego el gobierno federal, para estimular a los pequeños mineros, les daba un subsidio. Y era como más o menos se iba llevando.

Pero lo que iban sacando se lo repartían entre ellos. Y no todos eran leales (Entrevista, Cerro de San Pedro, 2008).

Conformaban el primer tipo de mineros, que se organizaban bajo la figura de "cooperativa", la carga de minerales, la venta al peso y liquidación según la cantidad de metal en la roca, además de los subsidios eventuales. Se los llamaba paleros. Además:

J: Había otra clase de mineros: los "gambusinos". La palabra "gambusino" no aparece en el diccionario y aquí se le llamaba gambusino. "Gambusino" es el pequeño...el minero solo, el que anda buscando vetas de oro, el que anda buscando pepitas de oro. Y había de eso. A ellos se les respetaba. Y ellos sacaban tierra, la movían, la lavaban, sacaban su oro y lo iban a vender a las joyerías. Yo: Ellos hacían todo el proceso.

J: Sí. Ellos hacían todo el proceso. Ellos molían...ellos lo buscaban, lo cortaban, lo trituraban, lo lavaban...

Yo: ¿Qué hacían, su propio socavón?

J: ¡No, no, no! ¡Si aquí tenemos como 300 kilómetros de minería! ¿Para qué iban a hacer otro socavón? No. Ellos iban donde sabían que estaban las vetas más buenas. Por eso eran conocedores. Y en eso estaba el mineral donde uno 
menos pensaba. Y era muy distinto a los que metían por tonelada. Yo conocí a muchos. Y esos se murieron. Todavía por ahí tengo alguna fotografía de los gambusinos (Entrevista, Cerro de San Pedro, 2008).

Los gambusinos buscaban las pepitas de oro según el conocimiento de los tiros que tenían. No cargaban mineral en bruto, sino que se dedicaban a buscar el metal casi puro.

Se comienza a evidenciar aquí una transformación en las relaciones de poder. $\mathrm{El}$ abandono de ASARCO sienta las condiciones para la emergencia de una nueva red de liderazgo. El trabajo cuentapropista, las cooperativas de pequeños mineros y el saqueo de los bienes de quienes emigraron caracterizaron esta etapa. La pérdida de importancia -al menos en términos formales- del sindicato minero y los canales mercantiles de la empresa permiten asumir que la subsistencia comenzó a correr por nuevos canales.

Esta transformación favoreció el surgimiento de una nueva red de poder en el poblado: la de aquellos que articulaban las cooperativas mineras y ocuparon el vació dejado por ASARCO. Se produjo un reacomodo de las familias: algunas migraron, otras se quedaron, cambió la importancia relativa de cada una. El suegro de Julián López se estableció como una persona de peso, por tener bajo su comando algunos resortes de los proyectos cooperativos. "Es que mi abuelo era medio cacique", dice Laura López en confianza. En efecto, su abuelo, el suegro de Julián, fue uno de los que organizó las cooperativas mineras de paleros tras la partida de ASARCO.

Hacia 1970 las cooperativas mineras de paleros en San Pedro estaban debilitadas y en sus últimos momentos. Se vieron envueltas en acusaciones de corrupción, fraudes y robo. Los habitantes del pueblo dicen que el suegro de Julián -el cacique López- y otros sacaron ventajas ilegítimamente del trabajo ajeno. Con el fin de las cooperativas esta red, que funcionó en los primeros veinte años tras el abandono de ASARCO, se desarticuló y dio paso a una configuración distinta de liderazgo.

\section{El fin de las cooperativas y una nueva red de poder}

Con la falta de empleo, los procesos migratorios y el desplazamiento del cacique López se volvieron a trastocar los roles en el ejercicio local del poder. El suegro de Julián y abuelo de Laura se vio obligado a abandonar San Pedro. También se produjo la migración del propio Julián. Por su parte, un antiguo habitante del pueblo, Agustín González, retornó de Chihuahua con un pequeño capital económico y comenzó a labrar su futuro político en el pueblo semi-abandonado.

L: Él trabajaba para la ASARCO. Cuando se termina el trabajo se va, porque mucha gente se va de aquí, con nuevo contrato con la empresa, pero para Barro Terán. O para Santa Bárbara, en Chihuahua. Entonces él allá hace su vida, encuentra a la señora, los muebles y luego vuelve aquí a hacer su vida, pero ya con una posición un poquito más alta. Se mete al PRI y el PRI pues en ese tiempo ganaba, tenía la presidencia municipal y ahí empieza a amasar su fortuna. Cuando llega la empresa minera él ya tenía como unos veinte años que ya decía que era ejidatario, que trabajaba la tierra y todo, pero no tenía un título de ejidatario que lo respaldara. Él dijo “yo soy ejidatario” y ya. Entonces llega la empresa... (Entrevista, Cerro de San Pedro, 2008). 
Buscando desacreditarlos, en particular a Agustín González, Laura, la hija de Julián, dice:

L: Lo que pasa es que a esta familia siempre la ha movido el dinero. Esta familia, él (Agustín) nació aquí. Su esposa es de Guadalajara. Pero en 1948, cuando se terminó el trabajo aquí en San Pedro, que se fue la compañía ASARCO, ellos se van para Chihuahua. Mucha gente se va para Barro Terán, Chihuahua, otra se va para Santa Bárbara. Entonces él se va a trabajar a la mina. Allá se encuentra a la esposa. Empiezan a tener su primer hijo, eran pobres, trabajaban en la mina, era peón de mina, se casa con la señora...pide a una mueblería todos los electrodomésticos para amueblar su casa, todo lo saca a crédito, la mueblería le da el crédito, le da los muebles, y jzas! Se desaparece de allá. Y se viene para acá. La mueblería lo busca por tierra y mar, no lo encuentra. Hubo gente que supo de eso, pero sin embargo no lo delató. Llega aquí a San Pedro, con muebles, con cosas y bueno...Antiguamente el que tuviera una radio en 1960, 1970 ya se le consideraba una persona rica (Entrevista, Cerro de San Pedro, 2008).

En el relato de Laura el retorno de los González a San Pedro es la forma de escapar tras cometer un fraude. El capital con el que vuelven e instalan su tienda de abarrotes es mal habido. Estos datos no sólo son importantes en términos de si son ciertos o no, sino que señalan el ánimo de las personas respecto de los otros. En 2009 uno de los hijos de los González era secretario municipal, otros trabajaban en Minera San Xavier. En aquel tiempo era la familia más fuerte de San Pedro. Para Laura esta situación está viciada desde su origen. La rivalidad política entre las dos familias se puede entrever en el relato.

En este nuevo contexto, sin cooperativas ni otra fuente alguna de empleo en la localidad, el municipio y la escuela se transformaron en las principales -sino únicas- instituciones que implicaban ingreso de dinero en el poblado. En tales condiciones, y en alianza con algunos de los que estaban retornando a San Pedro como los González, la familia Domínguez comenzó a encarnar la nueva relación de fuerzas. Aunque siempre residió en El Portezuelo la familia Domínguez se estableció como cabeza del municipio, ocupando su presidencia elección tras elección.

Los Domínguez representaron la hegemonía local en los tiempos posteriores a las cooperativas, cuando Cerro de San Pedro, la antigua y saqueada cabecera municipal, fue desplazada y superada económica y demográficamente por El Portezuelo. A su vez, supieron reconvertirse hacia fines de la década de 1990, aliándose a Minera San Xavier y renovando su liderazgo en el marco del conflicto minero.

\section{San Pedro y la llegada de Minera San Xavier: una disputa política truncada}

A principios de la década de 1980 la familia López había regresado a San Pedro. Lo propio habían hecho los González y la familia Domínguez que, como hemos visto, ejercía la hegemonía sobre el conjunto del municipio. Laura y su hermano se criaron en ese contexto. En sus palabras, la gente del pueblo "los veía raro", porque aparentaban haber llegado con un nivel económico superior al del resto de habitantes. Les "vestían de moños", los llevaban y traían de la escuela y los enviaban siempre con su almuerzo. Tenían, sin embargo, buenas relaciones con sus vecinos. Agustín González y Julián López fueron compadres en su momento: apadrinaron a sus hijos mutuamente. Es decir, en una 
primera instancia los vínculos se restablecían y reconstruían. Sin embargo la relación comenzó a quebrarse después que Julián, tras su retorno a San Pedro, comenzara a disputar ciertos espacios de poder. Las diferencias políticas y las actividades comerciales comenzaron a marcar ciertas desavenencias entre los antiguos vecinos:

Yo: ¿Y cuándo puso el negocio tu papá?

L: Llegamos de México y puso el negocio ahí nomás. La tienda se llamaba “El

Resbalón".

Yo: ¿Estaba aquí?

L: Ahí donde te dije donde vive la señora de los baños. Está así como un cerrito y ese lugar se llama El Resbalón. Porque está muy resbaloso... j te resbalas! Pues ahí están dos cuartos, ahí era la tienda "El Resbalón".

Yo: ¿Y qué vendían?

T: Maíz, frijol, leche en polvo, Coca-Cola, Fanta, Boing. Y ahí empezaron las desavenencias con Agustín. Ajá, por la tienda (Entrevista, Cerro de San Pedro, 2008).

Julián, además, era afiliado del Partido Acción Nacional (PAN) e intentaba hacer política en el pueblo contra Agustín González, que representaba al PRI. Fue Regidor -cargo electivo similar al de un concejal- y también sostuvo otros cargos, como el de representante popular ante el organismo de distribución de aguas por ejemplo. Según su relato:

Yo: Y usted cuando volvió aquí ¿Qué encontró?

J: Uhhhh! Encontré el pueblo sin agua. Encontré...muy duras las autoridades municipales, muy represivas.

Yo: ¿Eran Domínguez también?

A: No. Estaban allí metidos pero eran gente represiva de aquí ¡Gente que jamás pensé que iban a estar en la presidencia municipal! De lo más...de lo más mierda que hubo aquí en el pueblo, allí representándonos, de los más bandidos, allí representados en la presidencia municipal.

Yo: ¿Ellos de qué partido eran?

J: Del PRI. Y yo como buen panista [del PAN] llegué pechando calabazas por todas partes...estaba loco, nadie me hacía caso. Los tenían de aquí...es cuando llega la gente, que te digo, tenía a sus mismos hijos como esclavos. Y ya para colmo que no tenían estructura escolar. Muy deficiente. Y mis chicos tenían que estar en el kínder. Así que órale pues, con un señor y yo logramos que nos hicieran un kínder aquí. Venía una señora, eran voluntarias que trabajaban en la Secretaría de Obras Públicas. Señoras que nada tienen que hacer y se la pasan haciendo según ellos obras sociales ¡Jaja! Era la última vez que venían y quería hablar con ellas. Me las encontré en el camino. Busqué al presidente municipal y no estaba, y me dicen, que queremos esto y esto. ¿"Cómo le podemos hacer para que se junte la gente?" y dicen, "venimos la semana que viene". Venían los martes. "Yo les junto la gente" les dije. Junté unos chamacos y trajeron columpios para los niños (estas mujeres) y les pidieron juegos mecánicos y así empezaron a pedirles cosas. Cuando salí había un camión que hacía todos los horarios a ciudad capital ida y vuelta, había billar y tienda. Cuando regreso ya no había nada de eso.

Yo: Y no había agua tampoco.

$\mathrm{J}$ ¡ ¡Y no había agua! Lo único que lograron poner después fue luz eléctrica, pero agua no había. El agua fue últimamente, como en el 82. Y para eso no sabía filtrar el agua.

Yo: Y esta gente que estaba gobernando... ¿Por qué entonces?

J: ¡No hicieron nada! ¡Nada, nada! Se robaron puertas, ventanas, piedras, ... ¡ todo 
era un saqueadero! Llego y empezamos a los tirones, a los tirones (Entrevista, Cerro de San Pedro, 2008).

Julián llega con un proyecto político, opositor al oficialismo del PRI y comienza a gestionar obras y acciones por su cuenta. Descalifica a sus contrincantes casi con los mismos argumentos que ellos usan contra él -"era un saqueadero"; "se robaron puertas, ventanas, piedras"-, consigue traer el agua, gestiona un kínder, etc. Laura me habla de esto:

L: Cuando estábamos en la primaria teníamos fricciones con Agustín, porque nosotros no nos dejábamos mangonear. Pero toda la gente nos hablaba [...] cuando mi papá era regidor este...ya había dos formas políticas: PRI y PAN. Entonces los Domínguez no se servían tanto con la cuchara grande.

Yo: ¿Por qué?

L: Porque el PAN le disputaba espacios.

Yo: ¿Pero entonces los González andaban siempre con los Domínguez en eso? L:Sí. Eran aliados. Él era...dirigente de los mineros, de los campesinos, dirigente del PRI...tenía veinte mil cargos, que nadie en la vida le dio pero los tenía (Entrevista, Cerro de San Pedro, 2008).

El retorno de los López a San Pedro, en el contexto de un pueblo pequeño, casi abandonado, es significativo. El espacio de poder político y económico que implicaba el ejercicio del poder municipal y que se venía manejando a manos de los González en San Pedro, bajo la hegemonía de los Domínguez en la totalidad del municipio, encuentra un nuevo protagonista: los López.

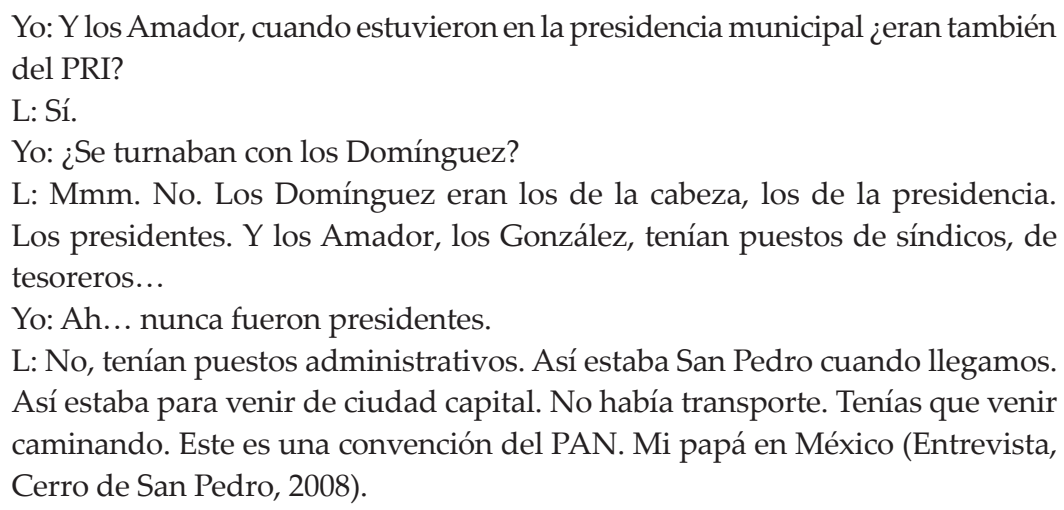

Estos espacios tienen que ver no sólo con cuestiones políticas sino con competencia económica, aunque aquí se superponen: en un pueblo vaciado económicamente, sin actividades rentables, la municipalidad constituía -y aún constituye- indudablemente no sólo una fuente de poder político sino de acceso a salarios y dotes monetarias. En este contexto, el ejercicio formal de la política implicaba una forma de ganarse la vida y facilitarse los negocios. La habilidad de Julián para hacerse espacios implicó una preocupación para los demás.

Hacia la década de 1990 Cerro de San Pedro se convirtió en un centro turístico dominical para la población de la vecina San Luis y los ocasionales turistas. Los folletos publicitarios del Estado lo presentaban como un pintoresco pueblo fantasma, colonial, con el atractivo de sus antiguas iglesias y los tiros abandonados. Sábados y domingos se llenaba de artesanos, puestos de comidas y visitantes. Se convirtió en lugar de descanso y algunos profesionales que residían en la capital compraron, edificaron o refaccionaron casas de fin de semana allí. 
Vinculado a esta situación comenzó a gestarse un proyecto de turismo alternativo a la minería, que se convertiría en una parte importante del conflicto contra la Minera San Xavier. Los López y otras familias del pueblo apoyaban este proyecto turístico. Dicho proyecto, a su vez, comenzaría a estimular disputas al interior de la familia Domínguez que, sin embargo, fueron saldadas en el proceso de instalación de Minera San Xavier, en la segunda mitad de la década de 1990, como hemos analizado en otros trabajos (Schiaffini, 2011 y 2016).

Al momento de plantearse la explotación del yacimiento de Cerro de San Pedro a manos de Minera San Xavier podemos encontrar una población que tiene ya perfilados ciertos conflictos internos que influirían de manera decisiva en la definición de los actores en pugna. Tanto la competencia entre dos proyectos sociales alternativos -turismo vs. Minería- como las disputas entre familias por el control del municipio, con el agregado, por supuesto, de otros factores y actores, marcarían fuertemente los años venideros. Al momento del inicio de las actividades de Minera San Xavier, estas disputas políticas estaban activas y encontrarían canales de expresión dentro del "conflicto socio-ambiental" que se desataría.

\section{Conclusiones}

Que unos se opongan hoy a la minería a cielo abierto y otros no en un mismo pueblo remite a procesos complejos y prolongados. Estas posiciones a favor o en contra nos revelan los alineamientos internos de la comunidad, sus pujas y disputas y las formas en que se instituyen históricamente las autoridades, el ejercicio del poder y la legitimidad de los líderes.

La transformación en los modos de explotar los minerales de Cerro de San Pedro fueron vividos como "crisis". Los ciclos de explotación y no explotación de las minas acarrearon transformaciones en las esferas políticas, familiares, laborales, en las necesidades de migrar o retornar. Se los recuerda como los momentos en que hubo que apelar a destruir lo acumulado, a saquear a los vecinos, a desobedecer a antiguos caciques y respetar a otros. Las crisis económicas en Cerro de San Pedro se vivieron como crisis de la autoridad o renovación de quienes ejercían el poder político en la localidad. Esto se hace evidente al analizar dichos procesos cuyos ecos continúan resonando en los conflictos actuales. Las disputas y rencillas que enfrentaron históricamente a facciones y familias encuentran nuevo oxígeno con el que combustionar en el marco del "conflicto socio-ambiental" del presente. Se imbrican y se retroalimentan, mixturándose con los elementos nuevos de las nuevas disputas.

Sin embargo, el análisis histórico, aún cuando en proceso constante de reformulación y mejora, permite entender algunos de los canales que conforman el sustrato de los conflictos contemporáneos. Todo conflicto tiene historia y éste no es la excepción. Por debajo de las apariencias del presente podemos rastrear las experiencias de más de un siglo de explotación minera moderna y los modos en que las poblaciones locales han intentado procesarla. 


\section{Q Bibliografía}

"Alimonda, H. (2008). La naturaleza colonizada. Ecología política y minería en América Latina. Buenos Aires, CLACSO.

"Auyero, J. (1998). La política de los pobres. Buenos Aires, Manantial.

"Bartra, R. (1978). El poder despótico burgués. México DF, Ediciones Era.

" Costero Garbarino, M. C (2008). “Minera San Xavier, San Luis Potosí: un estudio desde un punto de vista internacional" en Costero Garbarino M. C. (coord.), Internacionalización económica, historia y conflicto ambiental en la minería. El caso de Minera San Xavier: 59-103. San Luis - Potosí, El Colegio de San Luis.

"Delgado Ramos, G. (2010). "América Latina y el Caribe como reservas estratégicas de minerales” en Delgado Ramos, G. (coord.), Ecología política de la minería en América Latina: 17-57. México DF, CLACSO/ UNAM.

》 Gilly, A. (1982). La revolución interrumpida. México DF, Ediciones El Caballito.

"Martínez-Allier, J. (2006). Los conflictos ecológico-distributivos y los indicadores de sustentabilidad. Polis: revista académica de la Universidad Bolivariana 13: 59-102.

» Monroy Castillo, M. y T. Calvillo Unna (1997). Breve historia de San Luis Potosí. México DF, FCE/ COLMEX.

"Schiaffini, H (2011). Minería, conflicto y mediadores locales. Minera San Xavier en Cerro de San Pedro, México. Cuadernos de Antropología Social 34: 115-139.

» Schiaffini, H (2016). Las paradojas de defenderse. Articulación hegemónica y territorio en las luchas contra la minería a cielo abierto. Actuel Marx Intervenciones 19: 43-70.

》Sariego J. L, L. Reygadas, M. A Gómez y J. Farrera (1988). El Estado y la minería Mexicana. Trabajo, política y sociedad en el Siglo XX. México DF, FCE/ SEMIP.

"Svampa, M. (2008). "La disputa por el desarrollo: territorio, movimientos de carácter socio-ambiental y discursos dominantes". Ponencia presentada en el seminario Interrogating the Civil Society Agenda en la Universidad de Massachussets. Amhers, EE.UU. Disponible en Internet: http://www.maristellasvampa.net/archivos/ensayo43. pdf. Consultado el: 15 de mayo de 2018.

»Walter, M. (2009). "Conflictos ambientales, socio-ambientales, ecológico distributivos, de contenido ambiental... Reflexionando sobre enfoques y definiciones". Boletín ECOS 6. Disponible en Internet: http://www.gizartenatura.org/Archivos/Documentos/Secciones/20_es-ES_walter.pdf. Consultado el 25 de junio de 2016. 